\title{
Research on the Traditional Sports Intangible Cultural Heritage of the Yi Ethic Minority
}

\author{
Chuan Zhou, C.L. Deng \\ Sports Department of University of Electronic Science and Technology of China, Chengdu, Sichuan, China
}

\begin{abstract}
Study on the protective problems and countermeasures on the traditional sports intangible cultural heritage of the Yi ethic minority by using the research methods of literature, questionnaire etc. The research purpose is to better protect it. The results of the study think that the Yi people's sports intangible cultural heritage is very rich, but a lot of problems exist in the protection and inheritance, which are mainly the lack of a sound legal system, perfect management system, adequate protection funds, pay attention to the idea and the effective protection of protection channels. To solve these problems, we think it is from the legal, economic, government, education, travel, etc, to protect the traditional sports intangible cultural heritage of the Yi ethic minority.
\end{abstract}

Keywords - Yi ethic minority, traditional sports, intangible cultural heritage, protect, China

\section{彝族传统体育非物质文化遗产保护研究}

\author{
周川 邓陈亮 \\ 电子科技大学体育部, 成都, 四川, 中国
}

\begin{abstract}
摘 要 运用文献资料、问卷调查等研究方法, 对彝族传统体育非物质文化遗产及其保护面临的问题和对策进行研究。目的为更 好地保护传承彝族传统体育非物质文化遗产。彝族体育非物质文化遗产非常丰富, 但是在保护和传承上存在很多问题, 主要是缺乏健 全的法律制度、完善的管理体系、足够的保护资金、注重保护的观念、有效的保护渠道; 我们应该从法律、经济、政府、教育、旅游 等方面来保护彝族传统体育非物质文化遗产。
\end{abstract}

关键词 彝族, 传统体育, 非物质文化遗产, 保护, 中国

\section{1. 引言}

中国是一个有着悠久历史的文明古国，其广阔的土地 上居住着各种各样的民族，也容纳着各个民族间博大精深 的非物质文化遗产，其中，彝族就是这个古老中国的大家 庭成员之一，彝族人民用自己的双手和智慧在悠久的历史 文明中，创造了自己丰富多彩、独具特色的体育非物质文 化遗产，对促进中国少数民族地区体育事业的发展发挥着 重要的作用。在现代竞技体育迅速发展的今天，彝族传统 体育非物质文化遗产正濒临灭绝或逐渐消失, 所以保护和 传承彝族传统体育非物质文化遗产迫在眉睫。

\section{2. 彝族传统体育非物质文化遗产保护面临的问题}

\section{1 缺乏健全的法律制度}

中国虽然出台了一些关于非物质文化遗产保护的法
律, 如《非物质遗产保护法》、《文物法》、《著作权法》等, 但这些法律法规还不健全不完善, 而且可操作性不强, 不 能很好适应非物质文化遗产保护传承的需要。彝族作为少 数民族, 在保护传统体育非物质文化遗产方面的法律条文 非常缺乏, 更难找到针对性的条文支撑。所以, 中国急需 制定健全的有关非物质文化遗产保护的法律制度, 尤其是 像彝族这样的少数民族的非物质文化遗产的保护条例, 更 要加快制定。只有这样, 保护彝族传统体育非物质文化遗 产才有章可循, 有法可依, 彝族传统体育非物质文化遗产 才能得到更好的保护。

\section{2 缺乏完善的管理体系}

彝族传统体育非物质文化遗产, 是个比较纷繁复杂的 文化管理项目。它涉及彝族居民平常生活中的吃穿用品到 
传统节日的举办, 与平时的说话耕作到歌舞艺术, 包括彝 族人的口头文学、艺术行为、戏剧表演、传统技艺、民俗 文化、烹饪、茶、酒等等。所以，对彝族传统体育非物质 文化遗产的管理需要相关部门开展很多的工作, 这牵涉到 有关政府部门（如: 文化部、文体局、宗教局、旅游部、 民政局等）的合作与配合，但是在实际的工作当中，缺乏 统一的专门的彝族传统体育非物质文化遗产的管理部门, 导致职权不清, 遇到事情有推诿现象出现, 但是当遇到可 以获得经济利益的项目时，又会出现政出多门的现象。所 以，为了保护好中国彝族传统体育非物质文化遗产，相关 部门急需出台完善的管理体系, 将各部门职权划分清楚, 办事才能分工明细, 出了事情也知道谁管理, 谁担责, 不 至于乱套。

\section{3 缺乏足够的保护资金}

关于保护资金的缺乏，主要有两个方面。一方面，由 于像彝族这样的少数民族, 多半是属于贫困地区, 所以地 方上的财政收入本来就少，而彝族传统体育的非物质文化 遗产种类又很多，在资金投入方面显得力不从心。另一方 面，有关彝族传统体育非物质文化遗产的资金来源很单一 而且不固定，彝族传统体育非物质遗产保护的资金主要来 自于各级地方政府，而民间的资金投入又很少。此外，彝 族传统体育非物质遗产的资金投入也并没有成为各级政府 的一种自觉行为, 现行的一些财政拨款也是很难保证资金 到位, 只是在有非物质遗产名录护申报的时候才临时拨款。 由于资金的缺乏，基层政府很难保障对传统艺人、传承人 以及工作人员的培养。再加上硬件设备的不足，技术手段 的相对落后，更进一步的影响到了彝族传统体育非物质文 化遗产的挖掘、整理等保护工作, 甚至没有办法来对已经 面临濒危的彝族传统体育非物质文化遗产项目进行抢救。

\section{4 缺乏注重保护的观念}

由于“申遗”能够带来巨大的经济效益，所以目前“申 遗”已经成为了社会的热门话题。很多的地方政府，不惜投 入大量的资金，来申报国家级以及地方级的传统体育非物 质文化遗产。对于彝族地区来说，如果可以成功“申遗”, 这不仅可以当地经济发展提供一个支点, 而且还能成为彝 族地区政府官员政绩考核的指标之一，所以，彝族地区政 府部门在实际的工作中, 只是注重对非物质文化遗产的申 报与开发, 而缺乏注重对传统体育非物质文化遗产保护的 观念, 没能良好的处理好对传统体育非物质文化遗产的保 护与开发利用关系。彝族地区当地政府常常将非物质文化 遗产的开发作为发展当地经济以及提高当地知名度的一个
商机, 只是重视发展当地旅游业, 而缺乏注重对传统体育 非物质文化遗产的保护, 片面的追求保存传统体育文化的 外在形式, 而忽视传统体育文化的内在精髓。在注重发展 旅游项目的同时，只是将体育文化作为一种供人们消费的 产品, 进行一定的包装改造, 来迎合市场发展的需求。比 如: 在黄金周等旅游的旺季, 将彝族传统体育项目搬到演 艺大厅、人民广场等场所, 让前来参观的游客欣赏, 当成 一种娱乐, 这就让彝族传统体育非物质文化遗产脱离了它 原先赖以生存的环境, 失去了原有的内涵, 而成为一种非 常空洞的形式。甚至有些地方以保护传承传统体育非物质 文化遗产的名义任意篡改民俗文化, 歪曲文化遗产的内涵, 致使传统体育非物质文化遗产的原貌受到了很大的破坏。

\section{5 缺乏有效的保护渠道}

彝族传统体育非物质文化遗产有一个重要的特点就是 “口传身授”, 它不仅要以人体本身为存在, 以声音、形象 以及技艺为表现的手段, 还要以身口相传为文化链来进行 延续。假如从事民间传统体育艺术或技艺的艺人们逐渐减 少而又后继无人, 那么彝族传统体育非物质文化遗产就会 缺少传承人而濒临灭绝, 甚至消失。据彝族当地人介绍, 因为很多年轻人都外出打工了, 村里剩下的多半是老人, 一些传统体育非物质文化遗产因为缺少合适的传承人而无 法继续传承和发展, 虽然政府方面也确立了一些国家级的 传统体育非物质文化遗产项目的代表性传承人, 并且对这 些传承人进行了一定的资助和扶持。但是, 还有很多传统 节日的祭祀人员以及非物质文化遗产的传承人没有包含在 内, 这使得彝族传统体育非物质文化遗产失去了最为有效 的保护传承载体。这迫切需要政府加大对彝族地区传承人 的支持力度, 保证彝族传统体育非物质文化遗产的传承后 继有人, 这样才能更好的保护好中国传统体育非物质文化 遗产。

\section{3. 彝族传统体育非物质文化遗产保护的对策}

\section{1 从法律方面进行保护}

在各种外来文化以及快餐文化的冲击下, 彝族传统体 育非物质文化遗产的保护和传承不能离开法律、法规的保 护, 法律依旧是最安全、最为有效的保护方式, 假如没有 相关的法律政策作支撑、国家相关管理部门做后盾，传统 体育非物质文化遗产很容易被不法分子滥用或者盗用, 甚 至消失或消亡。所以建议出台一些相关的法律法规或者法 律条文, 比如《彝族传统体育非物质文化遗产保护条例》 等, 这是对彝族传统体育非物质文化遗产保护最有效、最 科学的保护手段。应该呼吁文化部、教育部、体育总局等 
相关部门联合起来, 参与有关彝族传统体育非物质文化的 立法研究, 尽快制定出有效保护和传承少数民族传统体育 非物质文化遗产的法律条文来。另外, 成立专门的彝族非 物质文化遗产保护科研小组, 加强对彝族非物质文化遗产 进行挖掘、整理、开发和研究等, 使得彝族传统体育非物 质文化遗产得到很好的保护、传承、创新。

\section{2 从经济方面进行保护}

在经济全球化快速发展的今天, 彝族传统体育非物质 文化遗产的保护必须拥有足够的资金补给才能保证各种政 策的具体落实, 比如: 成立彝族体育非物质文化遗产委员 会、修建彝族传统体育展示基地或成立彝族传统体育培训 基地等, 这都需要大量的资金, 而且需要调研考证、招商 引资、实地考察、网络宣传等, 也是需要一笔不小的费用, 如果没有足够的经济基础做后盾, 各个项目的保护都很难 实施, 最后只能停止或不了了之。要保护好彝族传统体育 非物质文化遗产，必须依赖政府的经济投入，与此同时， 还可以选择其它途径来进行集资, 比如, 面向广大社会和 企事业单位进行募捐, 以此来对彝族传统体育非物质文化 遗产进行补救、修复等, 来保障保护工作的顺利进行。

\section{3 从政府方面进行保护}

对于保护非物质文化遗产，一直以来都离不开政府的 支持, 政府作为保护的主体, 对非物质文化遗产保护工作 起着举足轻重的作用, 假如没有政府的有力支持, 非物质 文化遗产很可能就会被“边缘化”。所以，政府作为主导机 制, 常常肩负着对非物质文化遗产保护的重担，并负有扶 植和保护的责任。因此, 在保持彝族传统体育非物质文化 遗产上, 一方面政府需要采取有效的保护策略, 要在挖掘、 整理、收集、创新等方面，投入一定的专项保护资金进行 遗产抢救。尤其是保护好传统体育非物质文化遗产的优秀 项目, 影像文本、传统技艺等, 将它们以影像、文本或其 它形式再现出来, 或静态或动态。或者以博物馆的形式将 非物质文化遗产的原貌完整的保存下来; 另一方面就是, 相关部门要更进一步的健全和完善相关法规政策, 尽快的 制定出彝族传统体育非物质文化遗产保护的总体规划, 促 进彝族非物质文化遗产保护的立法工作, 明确彝族传统体 育非物质文化遗产保护的法律地位。可以这样说, 保护彝 族传统体育非物质文化遗产离不开彝族当地政府的支持和 推动, 政府在这里起着重要的主角作用。

\section{4 从教育方面进行保护}

彝族传统体育非物质文化遗产想要规范化、科学化、
普及化、长期化、有效化的传承, 就必须积极的与学校教 育相结合, 因为学校是传统体育发展的摇篮, 在学校开展 传统体育非物质文化遗产项目是其保护和传承的关键所 在, 必须拓展这一非物质文化遗产保护的有效途径。把民 族传统体育与学校体育良好的结合起来, 这样一方面可以 把彝族传统体育非物质文化遗产的内容进行有效的挖掘、 整理、研究和创新; 另外一个方面可以丰富学校体育课的 教学内容, 培养学生对体育课的兴趣, 增强学生的体育意 识, 提升学生的身心素质。比如: 摔跤、力搏、拔河、汤 秋千等, 很符合学生的兴趣爱好以及心理、生理发展需要, 而这些项目也基本不受场地和器材的限制, 参与的人数也 很随意, 方便开展, 轻松有趣, 具有广泛的传播性。所以, 我们可以根据学校的一些现有的实际条件, 把那些优秀的、 简单的、健康的、易于传播的彝族传统体育项目纳入到学 校的教育体制中来, 让我们丰富而独具特色的彝族传统体 育非物质文化遗产能够规范的、科学的、普及的、长期的、 有效的发展起来, 传播开来。这样才是对我们彝族的传统 体育非物质文化遗产有效的保护, 才能使它持续健康有序 的传承下去。

\section{5 从旅游方面进行保护}

对于保护彝族传统体育非物质文化遗产, 还可以从结 合自然景观的资源优势, 打造出传统体育非物质文化旅游 品牌方面入手。有学者认为从挖掘乡村旅游资源的意义可 以看出, 唤醒原生态的民俗文化, 就是对传统体育非物质 文化遗产的一种保护, 旅游开发与遗产保护并不矛盾, 而 是可以同步进行的。但也有学者持反对意见, 认为能够进 行旅游开发的少数民族地区毕竟只占少数, 而且旅游地区 很多都是出于经济目的才对传统体育非物质文化遗产进行 保护的, 所以只有部分传统体育非物质文化遗产受到了保 护, 而并不能让传统体育非物质文化遗产受到全面的保护。 很多时候在对非物质文化遗产进行保护与挖掘时, 容易演 变成“文化搭台、经济唱戏”的表演，而对保护真正的彝族 传统体育非物质文化遗产作用很小。笔者认为, 在彝族地 区利用地理人文自然景观, 将彝族传统体育非物质文化遗 产与旅游资源开发结合起来, 在一定程度上是能够对彝族 传统体育非物质文化遗产进行保护的。我们应当对彝族传 统体育非物质文化遗产进行活态传承与开发, 同时加强联 合, 积极打造产业舰队, 借此展示和弘扬彝族传统体育非 物质文化遗产的文化魅力与精髓, 以达到保护传承的目的。 


\section{4. 结束语}

保护彝族传统体育非物质文化遗产对促进民族和谐团 结、传承彝族传统文化、培育彝族民族认同、促进彝族区 域经济发展等具有重要意义，但是在保护传承过程中却面 临许多问题。我们必须加强宣传推广力度, 促进相关部门 积极配合, 鼓励社会各界人士积极参与到非物质文化遗产 的保护行列中来。但我们不能光喊口号, 必须用实际行动 来进行保护, 同时加大研究力度。在和谐社会构建背景下, 在国家对非物质文化遗产保护非常重视的环境中，对彝族 传统体育非物质文化遗产的保护和研究工作应与时俱进, 力求从彝族发展历程、文化可持续发展的视角来对其进行 保护，尽可能在实证的基础上多视角、多维度、多层面探 讨其保护和传承问题。

\section{参考文献(References)}

[1] Y. K. Zhao, "The research on the origin of the Tibetan traditional physical education and sustainable development," Journal of Qinghai Normal University (Philosophy and Social Sciences), Vol. 34, pp. 63-66, 2010.

[2] D. Z. Sun, X. F. Zhang and Y. N. Pang, "Research of the future tendency of the west national minority traditional sports_- Taking an example of the Yi Ethic minority," Journal of Xi'an Physical Education University, Vol. 26, pp. 45-48,2009.

[3] Y. H. Chen, J. X. Bai, "Development of national minority folk sports resources from perspective of non-material cultural heritage protection," Journal of Wuhan Institute of Physical
Education, Vol. 43, pp. 75-80,2009.

[4] Y. Zeng, "A Study on the Development and Protection of Intangible Cultural Heritage in Minority Areas," Journal of Guizhou University for Nationalities (Philosophy and social science), Vol. 74, pp. 70-73,2010.

[5] Z. X. Zhang, H. Pang, L. H. Zang, "The traditional sports protection research on the Xinjiang minority," Sports Culture Guide, Vol. 38, pp. 118-121, 2010.

[6] L. N. Dai, "The effective way to intangible cultural heritage to carry forward and inheritance," Zhejiang Archives, Vol. 56, pp. 50-51, 2012.

[7] Q. J. Wang, "Contemplation of traditional sport going into media in China_- Taking "Wulin Assembly" on CCTV-5 for example," Journal of Physical Education, Vol. 16, pp. 90-92, 2009.

[8] J. Z. Zhang, "Exploitation of folk sports cultural resources and the development of local social economy-Economic benefit analysis of Weifang International Kite Festival," Journal of Shandong Institute of Physical Education and Sports, Vol. 25, pp. 13-15+53, 2009.

[9] S. H. Wang, The protection and development of intangible cultural heritage of economics research, CD: Southwestern University of Finance and Economics Press, 2009.

[10] C. L. Deng, etc., "The Protective Problems and Countermeasures on the Traditional Sports Intangible Cultural Heritage of the Yi Ethic Minority," Journal of Hebei Institute of Physical Education, Vol. 28, pp. 94-96, 2014. 